\title{
Cultivation of students' engineering designing ability based on optoelectronic system course project
}

Danhua Cao, Yubin Wu, Jingping Li

Danhua Cao, Yubin Wu, Jingping Li, "Cultivation of students' engineering designing ability based on optoelectronic system course project," Proc. SPIE 10452, 14th Conference on Education and Training in Optics and Photonics: ETOP 2017, 104522Y (16 August 2017); doi: 10.1117/12.2269497

SPIE Event: 14th Conference on Education and Training in Optics and Photonics, ETOP 2017, 2017, Hangzhou, China 


\title{
Cultivation of students' engineering designing ability
}

\section{based on optoelectronic system course project}

\author{
Danhua Cao, Yubin Wu, Jingping Li \\ School of Optical and Electronic Information, Huazhong University of Science and Technology, \\ Wuhan, China 430074
}

\begin{abstract}
We carry out teaching based on optoelectronic related course group, aiming at junior students majored in Optoelectronic Information Science and Engineering. " Optoelectronic System Course Project " is product-designing-oriented and lasts for a whole semester. It provides a chance for students to experience the whole process of product designing, and improve their abilities to search literature, proof schemes, design and implement their schemes. In teaching process, each project topic is carefully selected and repeatedly refined to guarantee the projects with the knowledge integrity, engineering meanings and enjoyment. Moreover, we set up a top team with professional and experienced teachers, and build up learning community. Meanwhile, the communication between students and teachers as well as the interaction among students are taken seriously in order to improve their team-work ability and communicational skills. Therefore, students are not only able to have a chance to review the knowledge hierarchy of optics, electronics, and computer sciences, but also are able to improve their engineering mindset and innovation consciousness.
\end{abstract}

Our years of teaching practice indicates that, via this course, engineering consciousness and designing ability of students have been improved by a large margin.

Keywords: talent cultivation; project based learning; course project; engineering design; innovation consciousness

\section{INTRODUCTION}

This is an era of information explosion, full of social change and uncertainty. In view of the fierce competition in the market, enterprises can only survive with high quality products and continuous innovation. Therefore, it is critical to have talented employees for the enterprises to develop and keep growing. Generally the qualified employees have the following characteristics: they have a lofty sense of professional responsibility and professionalism and also, they can figure out and solve practical problems properly and are able to design complex technical systems; moreover, they usually have excellent interpersonal skills and spirit of cooperation as well as the motivation and ability of innovation ${ }^{[1-3]}$.

Huazhong University of Science and Technology is a comprehensive research university, and it is a cradle to train students with the ability of innovation. A great number of students majored in optoelectronics have graduated each year from the school of optoelectronic information which has a good reputation. In order to enhance 
undergraduate students' ability of engineering design, we carry out teaching based on optoelectronic related course group in junior year aimed at improving students' photoelectric system design ability, when different courses are combined and work together closely.

Since students lack the product design experience, we apply the project-based learning ${ }^{[4-5]}$ method. Through a project design, students can experience program demonstration and system realization in the whole process. Not only can it strengthen students' engineering design ability and engineering awareness, but also it is helpful for their future study and career.

Moreover, since students have long been accustomed to education methods called 'indoctrination', students lack of self-management and self-confidence to face challenges. We designed a fully open teaching environment to stimulate students' learning initiative and innovative thinking so that students improve their problem-solving skill in the process of overcoming difficulties and setbacks.

\section{OPTOELECTRONICS RELATED COURSE GROUP}

Undergraduate program for specialty in optoelectronic information science and engineering is divided into four parts: general education, information science courses, professional core courses and professional elective courses. The curriculum system design accords with the "integrated curriculum" principle, that is to break the barriers and increase the relevance between different courses so that they can serve for a common goal. For training the ability of system design, the curriculum system of optoelectronic related course group is shown in Figure 1:

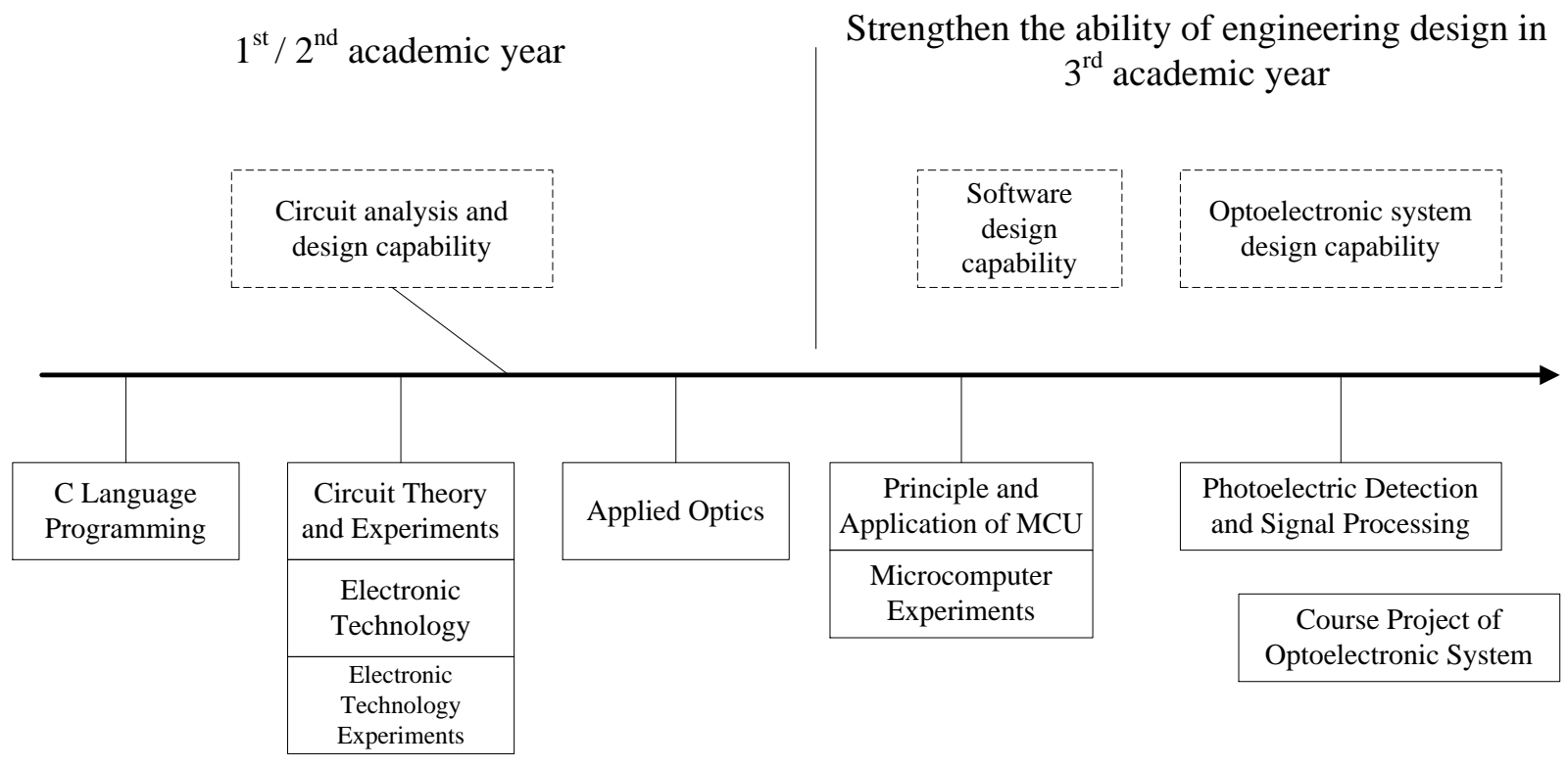

Figure 1. Curriculum group of optoelectronic system

Students are required to take courses including programming language, circuit design module, optical module in the first two years, and have a basic ability for program programming, circuit analysis and design. After that in the third academic year, they would study computer principle, photoelectric detection and signal processing courses. 
The curriculum system of optoelectronic related course group in the third year is shown in Table 1.

Table 1. Courses hours and teaching objectives

\begin{tabular}{|c|c|c|c|}
\hline Course & Hours & Semester & Teaching objectives \\
\hline $\begin{array}{c}\text { Principle and } \\
\text { Application of } \\
\text { Microcontroller }\end{array}$ & 56 & 5 & $\begin{array}{c}\text { To establish the cognitive of } \\
\text { microcontroller and interface technology }\end{array}$ \\
\hline $\begin{array}{c}\text { Microcomputer } \\
\text { Experiments }\end{array}$ & 16 & 5 & $\begin{array}{c}\text { To strengthen knowledge application } \\
\text { and programming ability }\end{array}$ \\
\hline $\begin{array}{c}\text { Optoelectronic } \\
\text { Detection \& Signal } \\
\text { Processing }\end{array}$ & 48 & 5 & $\begin{array}{c}\text { To establish the cognitive of } \\
\text { optoelectronic detector and detection } \\
\text { technology }\end{array}$ \\
\hline $\begin{array}{c}\text { Experiments of } \\
\text { Optoelectronic } \\
\text { Technology }\end{array}$ & 16 & 5 & $\begin{array}{c}\text { To enhance the ability of application of } \\
\text { basic photoelectric detection circuits }\end{array}$ \\
\hline $\begin{array}{c}\text { Optoelectronic System } \\
\text { Course Project }\end{array}$ & $3 \mathrm{~W}$ & 6 & $\begin{array}{c}\text { Conduct comprehensive design to } \\
\text { strengthen the system design capabilities }\end{array}$ \\
\hline
\end{tabular}

Students master professional knowledge systematically through the theoretical curriculum; then their comprehension has been enhanced through experimental courses; and finally their design ability would be strengthen through project.

\section{PROJECT BASED LEARNING FOR ENGINEERING DESIGN ABILITY}

\subsection{Teaching design}

\subsubsection{Students' skills developing and learning path}

Before the optoelectronic system project in junior year, students have mastered the comprehensive knowledge of electronic technology, computer technology, photoelectric detection technology, software design and so on. They are trained to design products according to the project goal and technical requirements, from the aspect of engineering design view. They learn how to carry out system scheme verification, components and detector selection, cost evaluation, schematic drawing, system board drawing, circuit board producing, circuit board welding, hardware and software debugging, learn how to write technical reports and make presentations so that students' abilities of the following aspects can be effectively improved:

1) Literature search

2) Scientific English literature review

3) Engineering design capabilities (systematically analyze problems and solve problems) 
4) Experimental skills

5) Scientific paper writing

6) Communication and team work

" Optoelectronic System Course Project" is a highly integrated, high-strength training projection. The relationship between learning path and students' skills is shown in Figure 2,

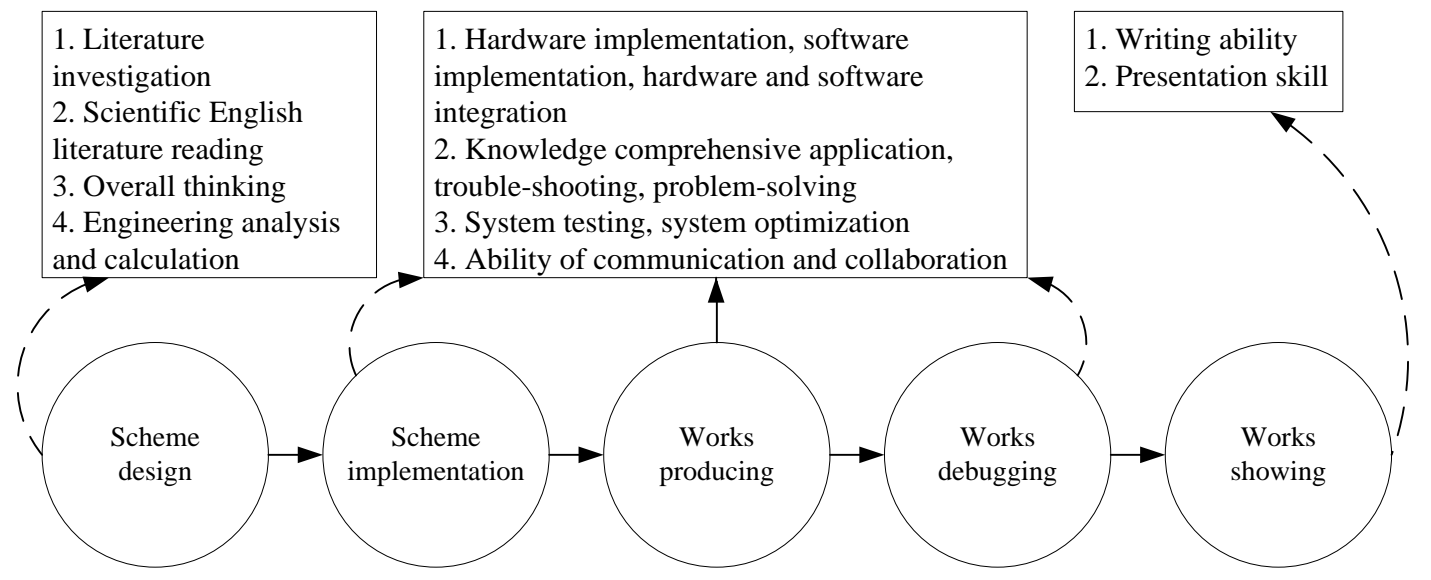

Figure.2. The relationship between learning path and students'skills

\subsubsection{The interaction between teachers and students}

To meet the teaching goal, the course project lasts one semester which includes 32 hours for classes, 40 hours for computer practices, 8 weeks for engineering design and 1 week for system debugging .

The " Optoelectronic System Course Project " help us build up learning community. Meanwhile, the interaction between teachers and students as well as the communication among students are taken seriously to improve their team-work ability and communication skill, as shown in Figure 3. 
Teacher's behaviors

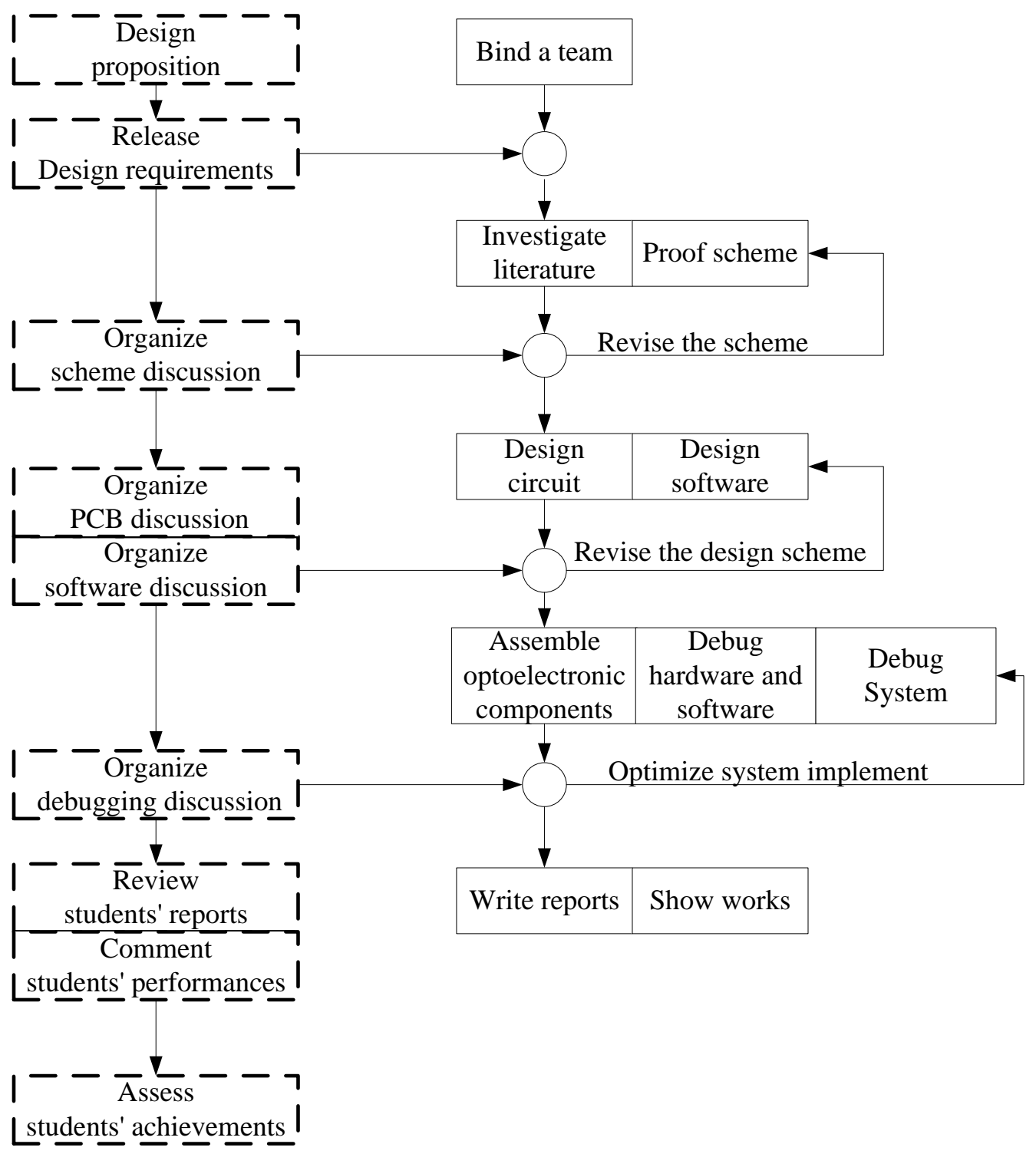

Figure.3. The interaction between teachers and students

The teacher is responsible for proposition design, proposing the design requirements, providing the necessary experimental conditions, verifying students' design, organizing the seminar, providing guidance, reviewing and assessing the student's performance.

Then students are required to read related literature according to the proposition, evaluate the system scheme and decompose design tasks. Then, students complete the design, make a presentation and finally write a report in a collaborating way.

In the "Optoelectronic System Course Project", teachers are always the leader of teaching activities which can be 
reflected in:

1) Through designing rational propositions, teachers guide students to actively review and re-learning of optical, electrical, computer science and other discipline knowledge. By this way, students are motivated to strengthen the construction of professional knowledge system;

2) Organize and conduct seminars. At the different stages of the project, such as scheme design, technology implementation and system implementation, teachers can correct students' misconceptions via discussion. In the same manner, students can deeply understand the proposition, engineering design methods and debugging methods. Also through frequently interaction between teachers and students, students' skills of engineering design, problem analysis and solving can be greatly improved.

It is essential for students to play an active role in learning path. Students' subjective initiative is reflected in:

1) Play their role in the team consciously, communicate and collaborate with other team members effectively;

2) At the stage of scheme proof, investigate literature consciously according to the proposition and analyze the information collected, then propose solution scheme.

3) At the technical realization stage, students recall what they have learned and put forward technical solutions. At this stage, students' ability to solve problems by applying the mastered knowledge is strengthened.

The interaction between teachers and students can be realized through seminars, QQ platform and face-to-face counseling and comments. Teachers and assistants give timely feedback to students and revise students' cognitive errors.

\subsubsection{Proposition design}

The propositions of "Optoelectronic System Course Project" are adjusted appropriately each year. The representative propositions include photoelectric guide car, photoelectric cardiotachometer, photoelectric motor speed controller, intelligent optoelectronic medical infusion controller and so on. In order to meet the teaching goals, the proposition should have the following characteristics:

1) Engineering meanings

The design proposition stems from the practical engineering application and has already had characteristics of typical photoelectric product. Through the training, students can understand the whole process of the product development of photoelectric system and enhance the students' engineering consciousness.

2) Comprehensiveness

To figure out the solution, students need to equip with the comprehensive knowledge of many courses, such as optical, electrical, computer science and optoelectronics basic theoretical knowledge, as well as basic experimental skills. Specifically, the proposition requires students to apply integrated knowledge of various courses. 


\section{3) Interestingness}

'Interest is the best teacher.' An interesting proposition will greatly stimulate students' potential, which would motivate students work more actively.

4) Visibility of works

The visibility of works can also enhance students' enthusiasm. Young people are like to show off. In order to win praise of teachers and classmates, students usually pursue perfection at the very beginning of product design and consciously work overtime.

\subsection{Stimulate students' initiative}

The initiative of teachers and students directly determines the ultimate effect of teaching. In order to change the passive learning attitude of students, we designed an open teaching environment to stimulate students' initiative.

\section{1) Openness of design tasks}

The proposition's technical requirements are assigned by teachers, but students need to work out the best plan to achieve the design goal, which is quite different from conventional course learning. In the process of developing their ability to solve practical problems, students should try their best to bring their subjective initiative into play.

\section{2) Openness of learning resources}

The design requires students to fully grasp the knowledge of optical, electrical, photoelectric detection, computer programming. Students should make full use of the library as well as network resources, such as teaching materials, books, device manuals, design cases, open source code and so on. It requires students to collect, organize and digest information quickly.

\section{3) Openness of learning environment}

With the advancement of learning practice, it extends from the classroom to the library, students' dormitory and laboratory. At the beginning of the project, teaching activities mainly occur in the classroom. The teaching focuses on the photoelectric system design related to EDA knowledge and industrial product design knowledge. During scheme proof, students turn into searching information from library or internet to figure out the technical route and implementation scheme. At the stage of the design, students complete design and simulation test in the dormitory or lab. During integrated system test, students assemble components, conduct performance testing and presentation in lab.

In this environment, students work in a team to experience each stage of product development, and thus students' subjective initiative has been effectively stimulated. Meanwhile, students' team spirit has been inspired.

\section{TEACHING PRACTICE}

In 2013, the school of optical and electronic information has invested more than 6 million RMB to construct the "Optical and Electronic Information College students public project laboratory" in order to provide students with complete experimental equipment, machining equipment, multimedia computer room and experimental debugging site which provide sufficient hardware support for teaching to be successfully conducted. The project 
schedule is shown in Table 2.

Table 2. The teaching schedule of Optoelectronic System Course Project

\begin{tabular}{|c|c|c|}
\hline Teaching schedule & Weeks & Description \\
\hline Giving lesson & $1-6$ & $\begin{array}{l}32 \text { hours } \\
\text { systematic teaching of electronic circuit and software } \\
\text { design }\end{array}$ \\
\hline Computer practice & $3-12$ & 40 hours \\
\hline $\begin{array}{l}\text { Comprehensive } \\
\text { design }\end{array}$ & $4-15$ & $\begin{array}{l}\text { Students carry out scheme proof, components and detector } \\
\text { selection, schematic drawing, system board drawing, } \\
\text { hardware and software design and debugging. }\end{array}$ \\
\hline $\begin{array}{l}\text { Assembling } \quad \& \\
\text { adjusting system }\end{array}$ & $15-16$ & Students finish performance test of the system in lab. \\
\hline Presentation & 16 & Students give presentation and submit report \\
\hline
\end{tabular}

The "Optoelectronic System Course Project " has been taught in HUST for more than ten years and has been named as school excellent course for four times. Some of students' representative design works are shown in Figure 4.

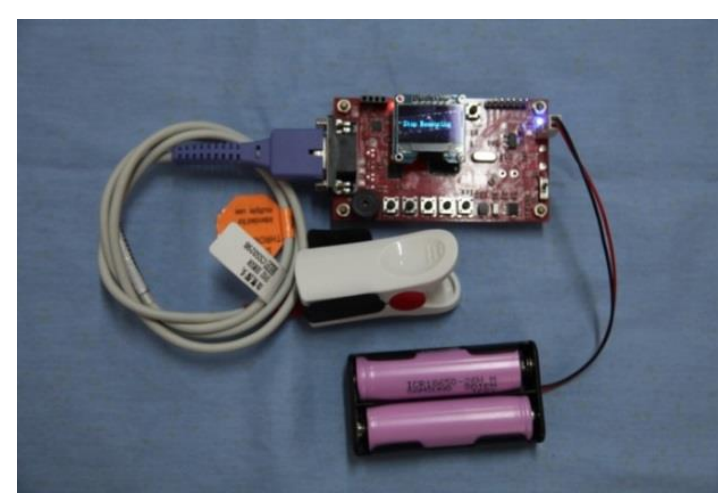

(a) oximeter

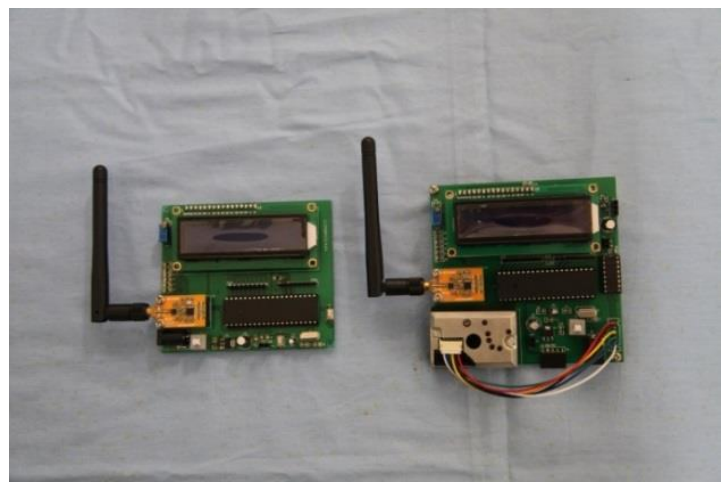

(b) PM2.5 monitor

Figure.4. Students' works

We also conducted a survey among students. Students said that they can deeply understand comprehensive knowledge learned through the project. Also, a successful design is a great positive feedback for students. By teamwork, they learn how to perform their duties as well as how to complete a challenging task efficiently. 

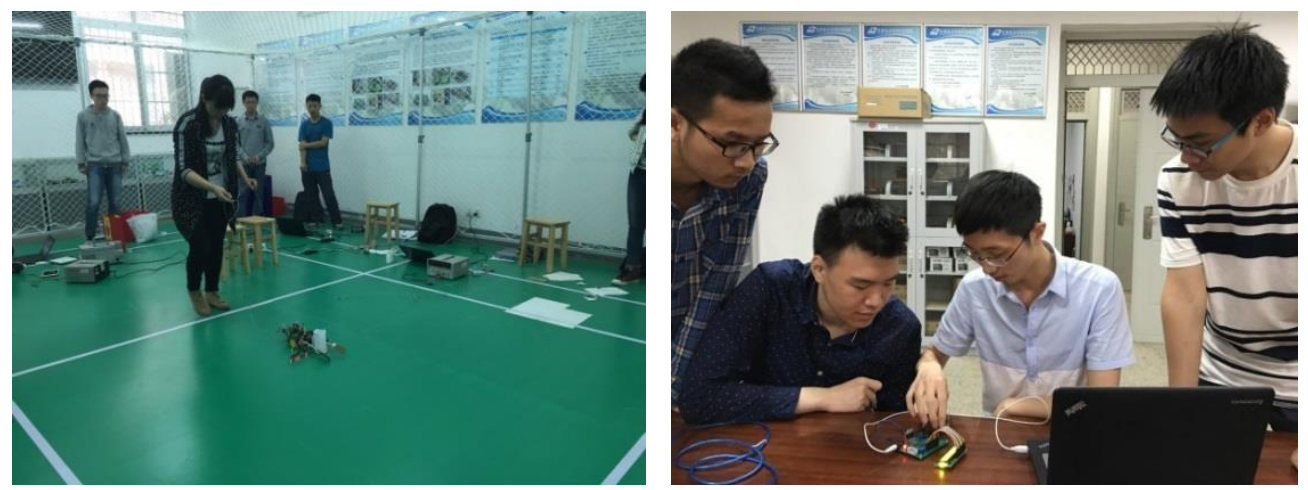

Figure.5. Students in testing and presentation

\section{CONCLUSIONS}

This paper takes the "Optoelectronic System Course Project" as an example to illustrate the training methods to enhance the students' engineering ability based on course group. This training is project-driven and combined with engineering application. By caring out comprehensive training, students' engineering design ability has been effectively improved. The success of the design makes students with a sense of accomplishment and self-confidence.

"Optoelectronic System Course Project" is a popular course in HUST, and has been taught for more than ten years. It has won the honor of excellent course several times. Because of the novel teaching method, most students are attracted and participate actively. " suffering while enjoying" is the common feeling of most students who have taken this course. Also, students take the design works and experience as an important proof material for themselves in job recruitment or application for graduation admission.

\section{References}

[1] Lin Jian, "The Annotation of Gebneral Standards for "A Plan for Educating and Training Outstanding Engineers" ”, Research in Higher Education of Engineering, No.1, 12-23 (2014).

[2] Li Hongmei, Jiang Zhibin, Zheng Yihui, "University Curriculum System Reformation to Strengthen the Cultivation of Engineering Ability”, Research in Higher Education of Engineering, No.5, 140-144 (2013).

[3] Lin Jian, "On Outstanding Engineers' Innovation Ability Training", Research in Higher Education of Engineering, No.5, 1-17 (2012).

[4] Zou Xiaodong, Yao Wei, Weng Mosi, "Innovation on Design-based Learning(DBL) Model for Engineering Education”, Research in Higher Education of Engineering, No.1, 17-23 (2017).

[5] C. M. Dym, A. M. Agogino, O. Eris, D. D. Frey, and L. J. Leifer, B: "Engineering Design Thinking, Teaching, and Learning”, Eng. Educ. 94(1), 103-120 (2005). 